doi: $10.15407 /$ ujpe61.03.0226

R.V. KOLODNYTSKA, V.B. KRYZHANIVSKYY, P.P. MOSKVIN

Zhytomyr State Technological University

(103, Chernyakhovsky Str., Zhytomyr 10005, Ukraine; e-mail: moskvin_pp@mail.ru)

\title{
MULTIFRACTAL ANALYSIS OF MARKS LEFT BY DROPLETS OF DISPERSED DIESEL FUELS WITH VARIOUS CHEMICAL COMPOSITIONS
}

\begin{abstract}
The multifractal analysis of the photos of droplet marks left by droplets of dispersed diesel fuels on the surface of a glass plate covered with a soot layer is performed. The dependences of the parameters for the multifractal spectra of mark areas on the component ratio in a mixture of diesel fuel and biofuels are found. The correspondence of the multifractal characteristics to their canonical forms is demonstrated. The developed numerical method can be used for the quantitative evaluation and analysis of the parameters characterizing the spatial fractal forms generated in air-fuel aerosols. Quantitative relationships between the parameters of multifractal spectra and the chemical composition of dispersed fuels are revealed.

Keywords: aerosol systems, air-fuel droplet mixtures, fractal states, dispersed liquid phase, multifractal analysis.
\end{abstract}

\section{Introduction}

The study of physical processes running at the sputtering of a liquid composes an important branch in the physics of dispersed states. It is aimed at researching the problem dealing with the creation of dispersed air-droplet media with prescribed properties. It is the creation of an optimal arrangement of fuel droplets in air at the dispersion of a liquid that substantially governs, e.g., the efficiency of the fuel ignition and combustion, and, hence, the functioning parameters of internal combustion engines. The realization of optimal thermodynamic conditions for the interaction of fuel droplets with an oxidizing medium makes it possible to considerably affect the processes of fuel combustion and, accordingly, the efficiency of using fuels with various chemical compositions in engines.

Liquid droplets dispersed in air form a complicated aerosol system with specific properties. Really, the aerosol mixture is formed from a set of droplets with identical physical and chemical properties. The mixture is formed, as a rule, by a single source or by sources that function under the same conditions. This situation should undoubtedly manifest itself in the appearance of specific kinds of a symmetry inherent

(c) R.V. KOLODNYTSKA, V.B. KRYZHANIVSKYY, P.P. MOSKVIN, 2016 to the whole aerosol system. In this respect, the simplest manifestation of this symmetry is the fact that the components of a system, i.e. droplets in the dispersed mixture, have geometrically similar shapes.

At the same time, the application of simple traditional mathematical expressions to describe complicated geometrical shapes that are observed experimentally in microscopic images of a dispersed liquid (droplet clouds and conglomerates, regions with different droplet concentrations, and so on) turns out, as a rule, to be of little use. However, it would be unreasonable to neglect the influence of such complicated symmetry shapes - to be specific, fractal - on the formation of final properties of the whole aerosol system.

In this case, the methods of fractal analysis may become efficient. The attention to advantages of their application to the description of a liquid in the dispersed state was attracted in works $[1,2]$. In particular, in work [1], it was shown that the length of the contour drawn along the surface of a dispersed liquid is a fractal variable, and the very process of air-droplet mixture formation should be considered as a fractal one. The corresponding reasoning as for the application of fractal analysis to the description of the state of an air-droplet mixture can be regarded as a development of traditional approaches to the description of a medium in the droplet state, for which

ISSN 2071-0194. Ukr. J. Phys. 2016. Vol. 61, No. 3 
the methods of statistical analysis are engaged for the calculation of the average droplet diameter [3] or the droplet size distribution [4].

At the same time, by applying the methods of fractal analysis to a whole macroscopic air-droplet system, we can obtain some useful information concerning the relative arrangement of dropet forms in air. This enables one to determine the parameters of a self-similar droplet state in the medium or, in other words, to reveal the internal symmetry of its aerosol state. It is the application of fractal analysis that opens prospects in obtaining the quantitative characteristics of this multiphase self-similar state with specific kinds of symmetry.

It seems natural to assume that there is a close correlation between the values of parameters that describe self-similar droplet states in aerosols, on the one hand, and the thermodynamic properties of a liquid and the conditions of its dispersion, on the other hand. The existence of the corresponding quantitative interrelations is promising for the purposeful control over technical facilities used to transform substances into the dispersed state.

Among the efficient approaches to the mathematical description of symmetry properties of complicated systems, the multifractal analysis (MFA) gained a wide-spread recognition [5-7]. Really, the application of the entire spectrum of multifractal parameters to the quantitative parametrization of a complicated system makes it possible to describe its state in detail.

It is worth noting that the application of monofractal analysis for the same purpose does not turn out so efficient. The main reason consists in rather a weak dependence of the major resulting parameter of fractal analysis, the Hausdorff dimension [6-8], on the properties and state of a modeled object. This situation is expected, if the monofractal analysis is used. Really, the theory of power series, which forms the basis of the fractal concept, assumes that the system is described by varying the power in the power-law functions. In so doing, we face a situation where relatively small variations in the powers give rise to substantial modifications of the described system properties. However, in view of the statistical character of the fundamentals of fractal analysis, it is rather difficult to determine them with a high accuracy in practice. As a consequence, the accuracy, with which mathematics describes the behavior of a system, inevitably decreases. So, it is the application of the MFA, in which the state of a system is described by a set of functions, that allows one to get rid of the indicated shortcoming inherent to the monofractal approach.

Works $[9,10]$ should be marked as examples of the MFA application to the description of aerosol systems. In particular, in work [10], the chemical composition of the atmosphere in Ukrainian and Slovenian towns during various seasons of a year was analyzed. The application of an approach, which is typical of the fractal analysis, made it possible to obtain recursive dependences for the corresponding concentrations of atmospheric components and calculate the multifractal parameters of an aerosol mixture. In work [9], the multifractal method was used to analyze the state of air in highly clean rooms intended for carrying out technological operations with semiconductor electronics. Even a very low concentration of uncontrollable impurities is known to be able to substantially affect the final parameters of semiconductor devices. An assumption that very low, practically at the atomic level, concentrations of impurities can be considered as fractal variables allowed the authors of the cited work to use the MFA to describe this aerosol state and to find the multifractal parameters of the system. The results obtained while describing aerosol mixtures at a quantitative level using the MFA stimulated the application of this mathematical method to the description of the state of air-fuel-droplet mixtures.

Therefore, this work was aimed at applying the MFA to the description of the air-droplet mixture state and the calculation, on its basis, of the multifractal spectra for dispersed liquids with various chemical compositions. The practical urgency of this work is confirmed by the fact that biodiesel fuels with various compositions were dispersed in our researches. The data obtained for the multifractal parameters of dispersed fuels with various compositions will make it possible to analyze their interrelation with the conditions of the air-droplet mixture formation.

\section{Parametrization of Dispersed Diesel Fuel in the Framework of MFA}

An important stage in the application of MFA to the description of a dispersed fuel state consists in the specific choice of the physical parameter, which would be the most informative and will allow the fractal parametrization. The principal role of this calculation stage was marked by the authors of work [9], where 
the parameters of absorption spectral lines for aerosol components were used to describe variations of the impurity concentration in air.

In this work, the area of the fractal structure surface, which could be observed on photos, was selected as a possible geometrical parameter that would characterize the system of dispersed liquid droplets. In addition, the value of this parameter should remain informative within the following stages dealing with the thermodynamic simulation of conditions required for the formation of a dispersed system. This is the parameter that forms a basic set of measure at the MFA realization in the presented calculations. The clear separation of this physical parameter will allow us to analyze its behavior under the dispersion conditions, and the parameter itself can be used in further thermodynamic calculations, e.g., of the surface energy of the dropet system.

The input information for the MFA of the surface area of dispersed droplets was obtained by analyzing photographic images. The main assumptions, which allowed the parameters of the structures shown in those images to be connected with the surface area of liquid formations, will be discussed in Section 3 in detail. The mathematical apparatus and the software of the MFA were described in detail in work [8], where they were used to describe the state of a semiconductor film surface.

According to the method of coarsened partitions in fractal analysis, the measure for every space cell is generated by splitting the space around the basic measure set into $N$ cells. As the cell measure $\mu_{i}$, the reduced area of the surface that finds itself in the cell, $\mu_{i}=S_{i} / S$ - here, $S_{i}$ is the elementary area, and $S=\sum_{i=1}^{N} S_{i}$ is the total area of the analyzed surface, which was determined from its spatial photographic image - was accepted as the measure of a cell.

Further, the method of coarsened partitions for the calculation of the parameters of multifractal spectra was realized, by following the procedure typical of this method [5-8]. For a cell with given dimensions, the partition function $Z\left(q, \ell_{k}\right)=\sum_{i=1}^{k} \mu_{i}^{q}$ was calculated, where $\ell_{k}$ is the normalized current length of the cube edge, which was used at the current step of the method of coarsened partitions, and $q$ is the power exponent that can change within fixed limits during the MFA. The cell scales were changed during the calculations (the cube size was enlarged) according to the formula $\ell_{k+1}=2 \ell_{k}$, where $k=1,2,3, \ldots$.
If a certain fractal symmetry is inherent in the researched physical system, the plot of the dependence of $\ln Z\left(q, \ell_{k}\right)$ on $\ln \ell_{k}$ is a set of points grouped along straight lines. For calculating the parameters of a linear regression between the indicated parameters, the least-squares method was used for every value of the number $q$, which was varied within the given limits. The results obtained for the coefficients of linear regression formed a basis for the calculation of all functions that comprise the multifractal spectrum of the system [5-8]. All indicated functions were calculated numerically. The developed original software was used to analyze the multifractal parameters of the area distribution for the marks left by the droplets of dispersed fuels with various compositions on a glass plate covered with a soot layer.

\section{Experimental Technique}

Experimental data, which were used as the input information for the MFA, were obtained on an installation for studying the process of diesel fuel dispersion. Its design and main characteristics were the same as in work [4]. The photographic images, which contained the information about parameters of the aerosol system, were obtained on glass plates, the surface of which was prepared as follows. First, the glass surface was covered with a layer of magnesium oxide. Then the surface was covered with a layer of kerosene soot about $0.2 \mathrm{~mm}$ in thickness. An incident droplet of fuel could punch the soot layer. This event was clearly detected by the appearance of a white spot with corresponding geometrical parameters on the plate surface. The system of such spots was photographed. The obtained photographic images were subjected to the MFA. The key stage of this technique aimed at obtaining the data concerning a state of the aerosol system is the creation of a soot layer, which must be uniform by thickness. Therefore, at the stage of producing the photographic images, soot was deposited on glass plates under identical experimental conditions.

Not less critical for the experiment is the choice of the period of action (the exposure time) of the droplet flux on a glass plate. The curtain shutter used in the installation allowed the droplet flux to be maintained at a constant level during its actions on the plate. The period of plate bombardment by fuel droplets amounted to $0.02 \mathrm{~s}$.

ISSN 2071-0194. Ukr. J. Phys. 2016. Vol. 61, No. 3 


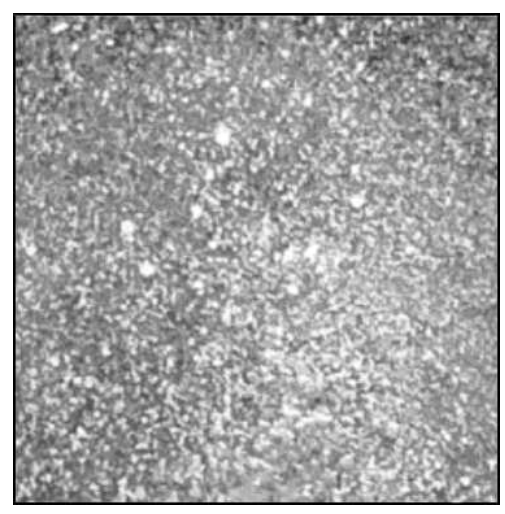

$a$

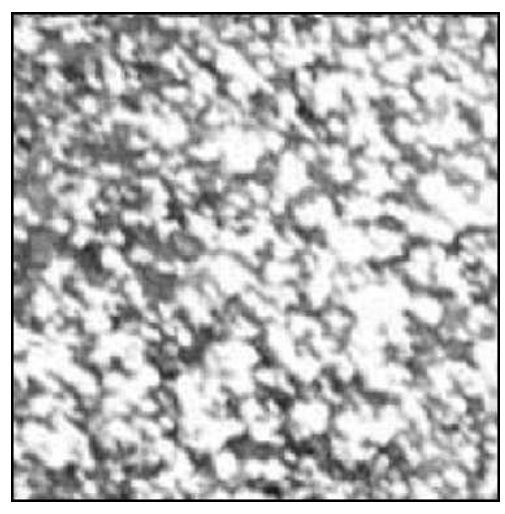

b

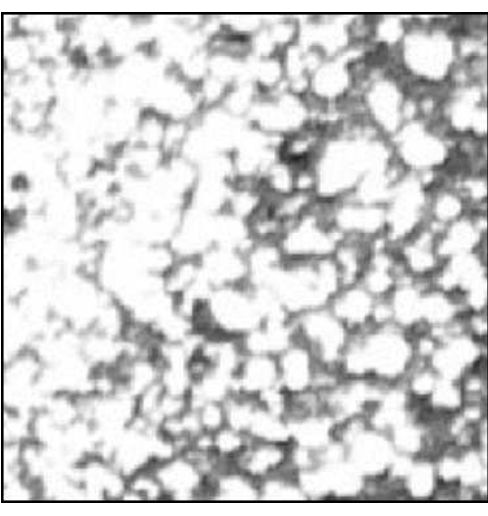

$c$

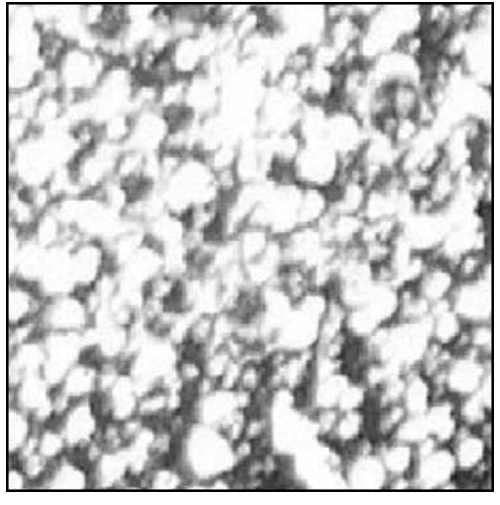

$d$

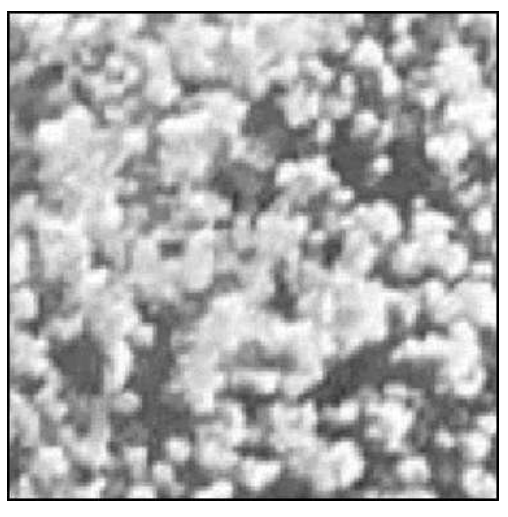

Fig. 1. Micrographs of the marks left by droplets of dispersed fuels with various compositions on the glass plate surface covered with a soot layer: diesel fuel (DF), $D_{0}=2.731$, and $\Delta_{80}=0.426(a) ; 30$ vol.\% methyl ether of rapeseed oil (MERO) + +70 vol. $\% \mathrm{DF}, D_{0}=2.618$, and $\Delta_{80}=0.411(b) ; 50 \mathrm{vol} \% \mathrm{MERO}+50 \mathrm{vol} . \% \mathrm{DP}, D_{0}=2.576$, and $\Delta_{80}=0.3585(c)$; 75 vol. $\%$ MERO +25 vol. $\%$ DP, $D_{0}=2.5989$, and $\Delta_{80}=0.471(d) ; \mathrm{MERO}, D_{0}=2.688$, and $\Delta_{80}=0.445(e)$

In the installation, injectors from the engine YaMZ-238DE2 were used; the injection pressure was $25 \mathrm{MPa}$, and the gas pressure was $1 \mathrm{~atm}$. The glass plate bombarded with fuel droplets was arranged at a distance of $250 \mathrm{~mm}$ from the injector cone.

Fuel mixtures with various compositions were prepared immediately before the experiment, which reduced the possibility of their stratification. The fragments of photographs used in the MFA are shown in Fig. 1. We would like to emphasize that, besides a careful monitoring of the fuel droplet mark formation on the glass plate throughout the experiment, the installation operational conditions with respect to various parameters were maintained constant.

The experiment aimed at obtaining the droplet marks was repeated twice, as a rule, for every composition of diesel fuel. At the same time, it should be noted that any fragment of the photo is enough for the calculation of a multifractal spectrum. This fact is associated with the capabilities of computational facilities and will be discussed below. As a rule, we used the central parts of photos in the calculations. The latter showed that different fragments of the same photo give rise to slightly different parameters of the multifractal spectrum. In particular, the variation of the Rényi number did not exceed 0.02 . This value was chosen as the quantitative evaluation of the error for the indicated parameters.

It is clear that the photographic image of droplet marks obtained following the described procedure reflects an instant state of the system of droplets in a selected cross-section of the droplet flux. The parameters of marks left by droplets in the surface layer on the glass plate depend at least on the geometrical shapes of droplets and the velocities of their motion. At the same time, the time interval of the image 


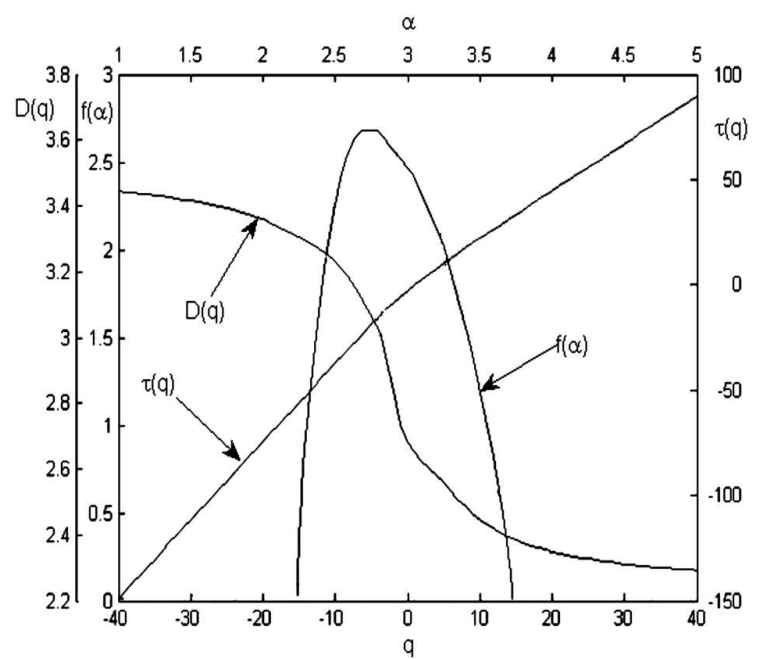

Fig. 2. Characteristic functions of multifractal analysis $D(q)$, $f(\alpha)$, and $\tau(q)$ for the image depicted in Fig. 1, $a$

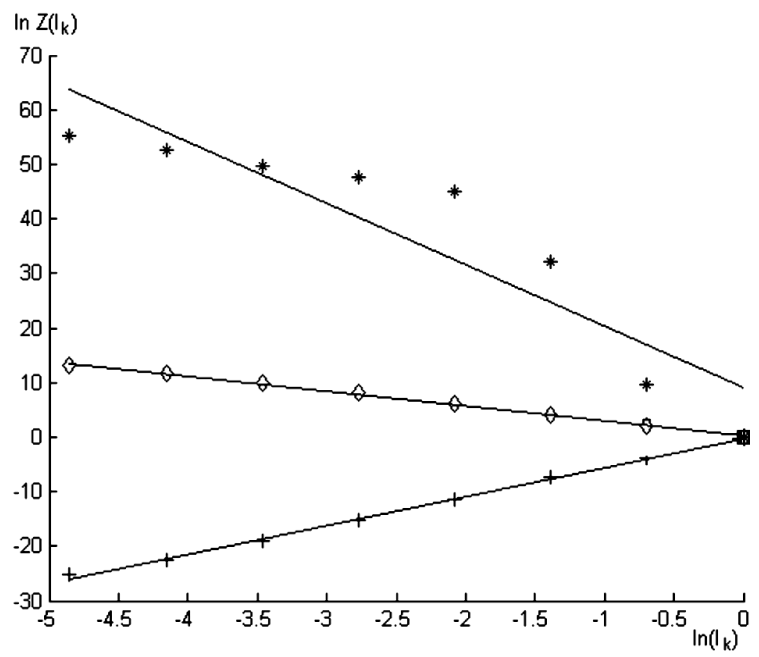

Fig. 3. Dependences of the partition functions $Z\left(q, \ell_{k}\right)$ on the normalized cube length $\ell_{k}$ for the image depicted in Fig. 1, a. The parameter $q=-3$ (stars), 0 (diamonds), and 3 (pluses)

formation on the plate (the droplet action time) was selected to be rather short. Supposing that the velocities of the majority of droplets do not differ considerably from their average value under the experimental conditions, we have all grounds to assume that the shape of droplet marks corresponds with a high probability to the geometry of droplets which left them. Therefore, while calculating the areas of spots in the photographic image, the obtained data should be interpreted as the areas of droplet surfaces.
According to the recommendations of works [6,7], as the most informative multifractal parameters that describe the surface structure, we selected the Rényi numbers and the order parameter $\Delta_{q \rightarrow \infty}=D_{1}$ $-D_{q \rightarrow \infty}$ (the measure of violation of the fractal symmetry). In the calculations carried out in this work, a typical value of the parameter $q$ did not exceed $q=$ 80 . The calculations showed that, in the case where the images were not larger than $256 \times 256$ pixels each and the values of the parameter $q$ were larger than 80 , the value of every next Rényi number, $D_{q+1}$, changed by less than $10^{-4}$ in comparison with $D_{q}$. Note also that the growth of the number of pixels in the photographic image, which were taken into consideration at multifractal calculations, above $256 \times 256$ resulted in a substantial growth of the computation time. At the same time, the corresponding final values of Rényi numbers changed very little at that. The calculations with the increased number of pixels in the image showed that the corresponding changes did not exceed 0.01. This value is smaller than the error associated with the choice of a photographic image fragment for the further analysis.

\section{Results and Their Discussion}

The approach described above allowed us to calculate the multifractal spectra and parameters for the images shown in Fig. 1. The calculation of characteristic MFA functions $\tau(q), f(\alpha)$, and $D(q)$ in accordance with works [5-7] testified that they correspond to their canonical forms. This means that the sequence of Rényi numbers is decreasing, and the function $f(\alpha)$ has a characteristic maximum. A typical form of characteristic functions obtained, by using the MFA of the images of diesel fuel droplet marks, are illustrated in Fig. 2 .

Note that, while processing the images of airdroplet mixtures formed by fuels with various compositions, none of the results obtained provided us with a pseudospectrum. According to work [6], the pseudospectra are characterized by the hierarchy $D_{0} \leq$ $D_{1} \leq \leq \ldots \leq D_{q}$, i.e. the sequence of Rényi numbers is increasing, and the probability density function for the fractal dimensionalities, $f(\alpha)$, has a pronounced minimum.

In Fig. 3, the typical dependences of the partition functions $Z\left(q, \ell_{k}\right)$ on the reduced length $\ell_{k}$ of the edge of a cubic cell are depicted, as an example, for several 
$q$-values in the method of coarsened partitions. The presented data are associated with the processing of the image shown in Fig. 1, $a$. The behavior of the function $Z\left(q, \ell_{k}\right)$ obtained for each other image in Fig. 1 expectedly turned out similar, although with different parameter values.

The results presented in Fig. 3 testify that the experimental data are grouped along several straight lines. The experimental results related to $q=-3$ have the widest spread with respect to the corresponding straight line. The data in Fig. 3 were chosen to demonstrate that the indicated regularities do not clearly manifest themselves for all values of the number $q$. At the same time, a typical value of correlation coefficients in the least-squares method for the indicated case, and for values $q<4$ in general, exceeded 0.9 , as a rule. The rather high values of correlation coefficients allow us to assert that the multifractal spectrum rather than the monofractal one is typical of the examined air-droplet dispersed systems, so that it is the multifractal parameters that should be used for the complete description of the dispersed fuel state.

The Rényi numbers for $q=0,1,2$ are known to be the most informative in the MFA [5-7]. At the same time, the comparative analysis of Rényi numbers obtained in this work for the indicated $q$ shows that those values differ weakly from each other. In particular, for the image in Fig. 1, a (diesel fuel), the obtained set of Rényi numbers is as follows: $D_{0}=2.731$, $D_{1}=2.703$, and $D_{2}=2.672$. Therefore, taking the statistical basis of MFA and, accordingly, the determination accuracy for the indicated quantities into consideration, it is possible to assume that each of those parameters can be used in the following comparative and thermodynamic analyses. Note that this situation does not contradict the theoretical fundamentals of MFA [5-7]. Nevertheless, we believed $a$ priori that the differences between the Rényi numbers $D_{0}, D_{1}$, and $D_{2}$ should have been larger.

This situation arising at the given stage of calculations can be explained as a result of the application of initially very small cells in the method of coarsened partitions. Those cells parametrize the surface of a dispersed liquid quite well even at $q=0$. Note also that the values of generalized Rényi numbers $D_{0}$, $D_{1}$, and $D_{2}$ substantially exceed two. This result corresponds to the problem, in which the area dimensionality is described for the surface that is considerably loose and nonplanar at the microlevel.

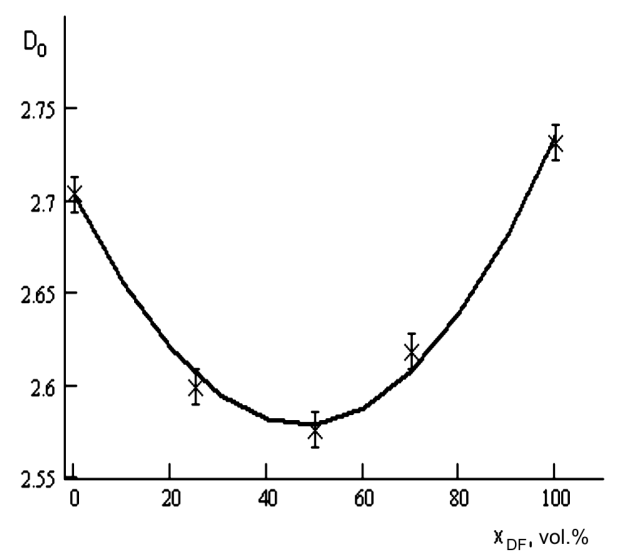

Fig. 4. Dependence of the Rényi number $D_{0}$ on the volume fraction of diesel fuel in the mixture DP + MERO. The symbols correspond to experimental data

The obtained numerical data for the multifractal parameters of a dispersed fuel make it possible to search for their interrelations with the fuel composition, i.e. the components of a dispersed medium. The set of corresponding interrelations between the Rényi number $D_{0}$, the order parameter $\Delta(q=80)$, and the fuel composition are shown in Figs. 4 and 5. It is important that the multifractal parameters were obtained under the same conditions of fuel dispersion and on the same equipment.

Different values of multifractal parameters obtained for dispersed fuels with different compositions testify to different internal structures and different symmetries of air-droplet mixtures formed by the applied equipment. Figures 4 and 5 demonstrate the existence of stable relations between the multifractal parameters of the system and the composition of a specific fuel.

In particular, Fig. 4 illustrates the dependence of the Rényi number $D_{0}$ on the dispersed fuel composition. The results of calculations show that the dimensionality of the area of the gas-fuel droplet phase interface in the researched dispersed system is minimum for the dispersed fuel mixture with the identical contents of its components. In practice, this result means that the mixing of the biodiesel fuel with the diesel one in the ratio $1: 1$ gives rise to a reduction of the possible contact area between fuel droplets and the air medium, i.e. to a lower dispersity of the air-droplet system. A probability for this situation to emerge, when the biofuel is added to the diesel one, 


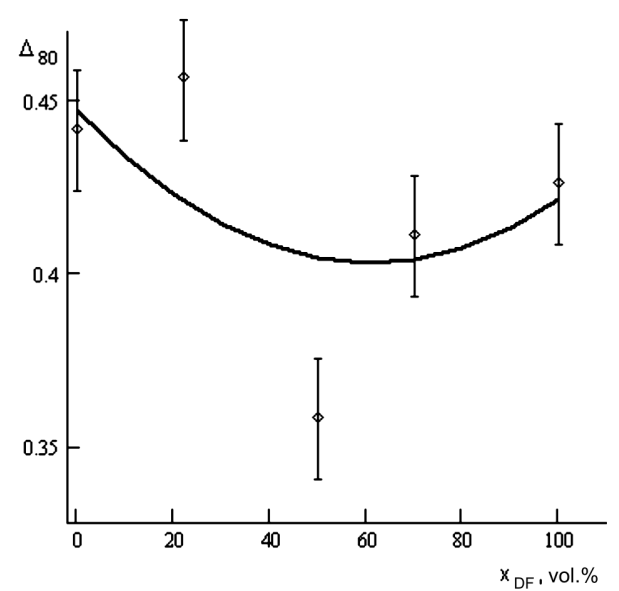

Fig. 5. The same as in Fig. 4, but for the order parameter $\Delta_{80}$

should be taken into account in order to provide the optimal combustion conditions for the latter.

Figure 5 demonstrates the results of calculations for the dependence of the fractal order parameter in the air-droplet mixture on the dispersed fuel composition. They testify that this dependence, similarly to the same dependence for the Rényi number $D_{0}$, has an extremum. From Fig. 5, it follows that, in general, the addition of the biofuel to the diesel fuel induces the compression of the multifractal spectrum of the system. As a result, the dispersed medium formed by a mixture of initial components taken in approximately the same shares tends to form a more ordered monofractal structure. We may suppose that the complication of a fuel composition by adding new components to it stimulates the growth of the total entropy of the liquid phase by means of an increase of its combination component, which gives rise to a change of the structure symmetry properties. The MFA statement about the relation between the Rényi number $D_{1}$ and the system entropy [5-7] confirms the latter conclusion.

The results obtained for the application of MFA to the description of the state of air-droplet mixtures demonstrate that the resulting quantitative information obtained from calculations of this type can be used to mathematically describe the state of this system and to purposefully control its properties.

\section{Conclusions}

To summarize, the results of multifractal analysis applied to the analysis of the images of marks left by droplets in air-fuel mixtures created by dispersing diesel fuels with various chemical compositions are reported. The fuel droplet marks are obtained on the surface of a glass plate covered with a soot layer. The parameters of multifractal spectra in aerosol systems, which were formed by dispersing fuels with various compositions, are calculated and analyzed. The Rényi numbers and the order parameters for the air-droplet mixture are demonstrated to strongly correlate with the chemical composition of dispersed diesel fuels.

1. S. Grout, C. Dumouchel, J. Cousin, and H. Nuglisch, Int. J. Multiphase Flow 33, 1023 (2007).

2. C. Dumouchel, Exp. Fluids 45, 371 (2008).

3. S. Sazhin, M. Qubeissi, R. Kolodnytska et al., Fuel 115, 559 (2014).

4. A.V. Ivashchenko and V.N. Goryachkin, Dvigat. Vnutr. Sgoran. 2, 41 (2011).

5. J. Feder, Fractals (Plenum Press, New York, 1988).

6. G.V. Vstovskii, A.G. Kolmakov, and I.Zh. Bunin, Introduction to Multifractal Parameterization of Material Structures (Regular and Chaotic Dynamics, Moscow-Izhevsk, 2001) (in Russian).

7. S.V. Bozhokin and D.A. Parshin, Fractals and Multifractals (Regular and Chaotic Dynamics, Moscow-Izhevsk, 2001) (in Russian).

8. P.P. Moskvin, V.B. Kryzhanovskii, L.V. Rashkovetskii, P.M. Litvin, N.V. Vuichik, Zh. Fiz. Khim. 88, 1194 (2014).

9. S. Klement, J. Nittman, K.W. Kratky, and W.P. Acito. Aerosol Sci. Technol. 20, 100 (1994).

10. V.D. Rusov, R. Ilic, R. Jacimovic, V.N. Pavlovich, Y.A. Bondarchuk et al., Atmosph. Climate Sci. 1, 120 (2011).

Received 02.08.15.

Translated from Ukrainian by O.I. Voitenko

\section{Р.В. Колодницъка, В.Б. Крижанівсъкий, П.П. Москвін}

МУЛЬТИФРАКТАЛЬНИЙ АНАЛІЗ

ВІДБИТКІВ КРАПЕЛЬ РОЗПИЛЕНОГО ДИЗЕЛЬНОГО ПАЛИВА РІЗНОГО ХІМІЧНОГО СКЛАДУ

Р е $з$ ю м е

Реалізовано метод мультифрактального (МФ) аналізу площі поверхні відбитків крапель розпиленого дизельного палива, що отримані на поверхні скляної пластинки, покритої шаром кіптяви. Вхідною інформацією для МФ аналізу слугують фотографічні зображення отриманих відбитків. Знайдено параметри МФ спектрів площі поверхні відбитків в залежності від складу суміші дизельного та біопалива. Показано, що МФ функції системи відповідають своїм канонічним формам, а розроблена числова методика може застосовуватись для кількісних оцінок та аналізу параметрів стану площі просторових фрактальних форм, що утворюються у аерозольній паливно-повітряній системі. Виявлені кількісні взаємозв'язки між параметрами МФ спектрів і хімічним складом розпиленого палива. 